\title{
The Object(s) of Phenomenology
}

\author{
Thomas Arnold ${ }^{1}$
}

Published online: 19 April 2020

(C) The Author(s) 2020

\begin{abstract}
Object-hood is central to Husserl's work, yet he employs several different notions of object-hood without clarifying the differences; his work thus offers rich and nuanced reflections on object-hood, but in a theoretically underdeveloped, at times even paradoxical, form. This paper aims to develop Husserl's theory of objects systematically. In order to achieve this I distinguish five object-concepts operative in Husserl's phenomenology and prove that they are not co-extensional. I also argue that they form a layer in terms of transcendental constitution, one implying the other. I conclude the paper by exploring Husserl's paradoxical claim that the absolute is not an object. From these considerations, two meta-phenomenological lessons emerge: (a) objecthood is not total (there are not only objects); yet (b) we cannot escape objectification while engaged in phenomenological reflection.
\end{abstract}

\section{Summary}

Object-hood is fundamental for phenomenology as a theory of intentionality, because every intentional act is directed at its object; intentional acts constitute objects. Husserl himself however seems to employ several fairly different notions of object-hood throughout his writings; the terms "object" (Gegenstand) or "objectuality" (Gegenständlichkeit) are used interchangeably as well as ambiguously. The main goal of my paper is to untangle and clarify the different concepts of

\footnotetext{
This paper is a result of a DAAD-project (91671488) at the Center for Subjectivity Research (Copenhagen). I would like to thank the German Academic Exchange Service (DAAD) as well as Dan Zahavi for the opportunity of working on Object-hood at the Center in beautiful, beautiful Copenhagen. I would also like to extend many warm thanks to all researchers at the Center for enlightening discussions of this rather abstract topic. Finally I would like to give thanks to an anonymous reviewer and the editors for offering very helpful criticisms, following which I hope I have made the paper as accessible as possible.
}

Thomas Arnold

T.Arnold@uni-heidelberg.de

1 Akademischer Rat, Philosophisches Seminar, Universität Heidelberg, Schulgasse 6, 69117 Heidelberg, Germany 
object-hood in play in Husserl's phenomenology. This includes a discussion of the limits of object-hood.

In Sect. 2 I introduce the problem and point out that "object" is both an important as well as problematic term not just for phenomenology, but for other forms and traditions of philosophy as well.

In Sect. 3 I distinguish five different notions of object-hood employed by Husserl. According to these different notions of object-hood, an object is either something at all (formal notion), something intended (intentional notion), something numerically identical (mathematical notion), something about which something true can be predicated (logical notion) or something that exists (existential notion). I consider the question whether these concepts all have the same extension. I prove that they do not.

In Sect. 4 I delve into the question of how the different concepts are related to each other in terms of transcendental constitution and how they are to be ordered. In some passages, Husserl indicates a preference for some notions of object-hood by distinguishing between "proper" or "primary" objects and merely "potential" or "secondary" objects. I therefore also take a closer look at what Husserl seems to take as the decisive difference between the different layers: the constitution of identity through logical synthesis which allows for the appearance of objects proper. In the course of this discussion I show that the concepts of object-hood form a genetic layering.

In Sect. 5 I conclude the paper by examining what Husserl has to say about the limits of object-hood, in light of his claims that the ur-ego, the core of subjectivity, is not an object at all or in any sense. This gives rise to what I call "the paradox of the absolute", revolving around the inconsistent attempt to theorise about something (an object even in the weakest sense) which at the same time is denied the very status of being something at all. I end with two meta-phenomenological lessons: (a) object-hood is not total; yet (b) we cannot escape objectification while engaged in phenomenological reflection-even in reflections on the absolute and the limits of object-hood.

\section{Introduction: Problems with Object-hood}

The "transcendental universal-problem" is that of the "transcendental constitution of all transcendences, yes, of all objectualities in general" (Hua XVII, p. 259). The object (Gegenstand) or, put more abstractly, objectuality, (Gegenständlichkeit) is fundamental for Husserl's phenomenology. It is because phenomenology is- to a large extent - a theory of intentionality and intentionality is the property of beingabout-an-object or being-directed-at-an-object. All acts of perceiving, valuing, judging are about objects; whatever we can talk about meaningfully is, in some sense, an object (Held 1966, p. 146). So object-hood forms part of the topical or thematic core of phenomenology's research agenda. Since phenomenology itself is an objectdirected activity, object-hood is also a topical theme of phenomenology's reflexive self-grounding, the phenomenology of phenomenology or meta-phenomenology. 
While object-hood is fundamental to phenomenology and phenomenology itself seems well equipped to explore it, Husserl himself employs several different objectconcepts at different occasions, without ever clarifying or conceptualising the differences; the different concepts can be grouped or ordered in various ways (cf. Keiling 2010, p. 114, Erhard 2014, p. 132). The task of categorizing, explicating and relating these different concepts of object-hood is made more complicated by the fact that "object" usually works as an "operative" term (Fink 1957), i.e. it is employed, but not explicitly thematised or further elaborated on. Even within his formal ontology as presented in Formal and Transcendental Logic, which Husserl sets up as a theory of possible objects (in general) (Hua XVII, p. 149), we find diverging accounts of object-hood. Thus we are faced with a disconcerting lack of conceptual clarity regarding one of the most fundamental terms in phenomenology. The main aim of this paper is therefore to clarify Husserl's theory of objects.

Before we get into Husserl's account of object-hood, I would like to point out that the question of what constitutes an object remains non-trivial as well as important outside phenomenology too; object-hood appears to be an equally tradition-spanning as well as generally elusive topic. Applied to the history of philosophy, the objectconcept permits bridging gaps between many different epochs, kinds, and styles of philosophy as the concept of an object is fundamental not only for phenomenology, speculative, and analytical ontology but for hermeneutics, critical theory, and postmodern thought as well (if only as the target of criticism). Going further back one could also add German Idealism and even (Neo-)Platonism to those areas of philosophy for which the object/non-object distinction seems to be central (cf. Tugendhat 1976, pp. 36-39 for the relation between antique theories of being and modern discussions regarding object-hood), even though the term "object" came into use only during the first half of the 13th century (Kobusch 1984, p. 1027).

As in the case of Husserl's phenomenology, object-hood appears to be of interest to many currently ongoing debates, including those about the existence of abstract objects and those surrounding the so-called "New Realism" or "object-oriented ontology". Yet within theoretical philosophy the word "object" has no "truly standard designation" (Laycock 2010, Section 1.1) and since nature does not fix the use or the meaning of the term "object" (Putnam 1987, p. 36), we can only look at how the term is used in the various contexts of different ways of thinking and talkingand how philosophically fruitful these are.

Potentially, this is the only way of dealing with the term "object", as according to Frege, the term is simply undefinable (Frege 2008, p. 13). Like other fundamental notions, "object" seems to be primitive, incapable of further conceptual analysis, since every analysis would necessarily result in a circular definition along the lines of " $x$ is an object iff $\varphi(x)$ ", where " $x$ " merely stands in for "any object". The property of being an object (object-hood) therefore appears to be what McGinn calls a "logical property" (McGinn 2000, p. 31), i.e. it would trivially apply to all conceivable objects, as any object is indeed necessarily an object.

While this might be true, it does not really explain the (relative) lack of discussion, since similar problems occur with regard to "being" (and maybe "identity" and even "truth"), as Aristotle has famously pointed out, which has not stopped philosophical engagement with these terms and concepts so far. The impossibility of 
analysis in a strict sense does not imply the impossibility of rigorous philosophical discussion about un-analysable terms, as Williamson stresses (2000, p. 5). While we should not expect a strictly non-circular definition of it, we can still aim for a characterisation of the concept(s) of an object, elucidating what objects are without offering necessary and conjunctively sufficient conditions of object-hood. Struck by a similar problem within the philosophy of mathematics, Gödel has explicitly and forcefully hailed phenomenology as a means of achieving such further clarification of the meaning of these basic terms ("Sinnklärung") without simply trying to (mathematically) define or analyse them (Gödel 1995, p. 382). So while the following paper is mainly an exercise in Husserl-exegesis, we should keep in mind that Husserl's rich phenomenological considerations of object-hood might be able to contribute to a more general systematic debate about the nature of objects.

Regarding the textual basis of my account I will mostly rely on Formal and Transcendental Logic since it is here that Husserl develops his late formal ontology, which after all deals with exactly such concepts like "object" which are "transformations of the something-at-all", "something" being an empty or formal concept (Leerbegriff) through/in which objects in general are thought (Hua XVII, p. 112). Formal ontology is therefore a theory of possible objects.

\section{Extensions}

We will start our investigation by distinguishing five concepts of object-hood.

1. The "formal fundamental category of object" (Hua XVII, p. 119) is simply "something" or "something at all", on which all other, non-formal characterisations rest. It is an empty concept for Husserl as nothing is just an object.

2. According to the intentional concept of object-hood an object is essentially an intentum, i.e. the non-subjective pole of an intentional act. This corresponds to the literal meaning of "obiectum" as that which is thrown against or towards us (qua subjects), from Latin ob-icio, "I throw".

3. Furthermore, an object can be understood as something identifiable (Hua XVII, pp. 164, 171) or even numerically identical (Hua XVII, p. 171); something which can be counted or can be an element of a set. We might thus call this notion the mathematical or numerical one.

4. According to the logical perspective, an object is the "subject of possible true predications" (Hua III, p. 15) or "the substrate of possible determining predications in general" (Hua XVII, p. 77) or simply the "substrate of possible predications" (Hua XVII, p. 177). While these definitions might differ in details, we will summarise them under the heading "logical notion".

5. The existential notion of object-hood equates objects with existing entities. An object proper in the existential sense is something that is real or ideal. For Husserl, this excludes impossibilia (Erhard 2014, p. 135, referring to Hua XL, p. 321), yet 
includes not just medium sized dry goods, but also what are now usually called abstract objects. Numbers for example are objects in this sense too.

According to these different notions of object-hood, an object is either something at all (formal notion), something intended (intentional notion), something numerically identical (mathematical notion), something about which something true can be predicated (logical notion) or something that is or exists (existential notion). All these notions of object-hood form topical themes of phenomenological research which aims at explicating how an object in each sense appears to or is constituted by a subject. This list of different object-concepts immediately provokes what we might—with Husserl—dub the "problem of different layers of objectualities" (Hua XXXIX, p. 8), i.e. the question how these different concepts are related to each other. This encompasses both the (static) question regarding their extension and relative strength as well as the (genetic) question regarding their relations in terms of transcendental constitution.

To get a grip on the issue we will proceed through a set of cases, considering the possibilities of something (we will also say "entities" or "things" by which we merely mean the plural of "something") instantiating some, but not all of the concepts, thereby establishing that the concepts are not all co-extensional. Trivially, the formal notion is fundamental since it is implied in all other notions; the question whether there is an entity which is not even an object in the formal sense will occupy us in the last section. For now we will only consider the remaining four, non-formal notions.

Something that instantiates all concepts of object-hood is easily imagined. Such a-so to speak-maximally objective (or objectual) object would be something (1) which is intended (2), identical (3), the substrate of predications (4) and which actually exists (5). Keeping in line with traditional examples, my table and the Platonic bodies can serve as examples for the two main groups of existing, namely real and ideal objects respectively. My table is something; I am now (while writing this) intending it as a topical theme as well as seeing it (it even has the distinction of having been referred to by several subjects, like my wife, our daughter and the carpenter who has made it); it is also identical to itself; it is the substrate of predication (since I am saying things about it); it also exists (arguably). More specifically it exists by being a real thing, or, since "real thing" is almost a tautology (as "res" means "thing" in Latin), my table exists as a medium sized dry good within space-time, materially. Mutatis mutandis the same goes for the Platonic bodies, although they are given through categorial instead of sensual intuition and exist ideally or as what some used to call an "abstract" object and outside space-time, immaterially. Their existence can be proven, their essence defined through mathematics.

The last, existential notion, is probably easiest to subtract. There are a lot of entities which do not exist in the full sense of either being real or ideal in the way Husserl applies these terms. The largest natural number for example can be proven not to exist. Also the ideal table does not really exist (because it is ideal). It is of course possible to redefine "exist" or "existence" in such a way that both the largest natural number and the ideal table exist in some un-real, un-ideal sense, but this is not in 
accordance with Husserl's understanding. Both examples however are objects in the senses 1-4: they are something, they are intended, they are (arguably) identical to themselves, they are substrates of predication.

As there are many things which do not exist, there are also many entities which are not intended. It is obviously impossible to name particular examples of those, since in doing so they would become intenta. We can only point towards the general group of things which are not intended. The class of non-intenta is infinitely big, of course, since already an infinite amount of natural numbers are not, were not and will never be intended individually. The same goes for most particles, probably anything outside our light cone, also the "unknown unknowns" (as made famous by Donald Rumsfeld) etc. And this only concerns (possibly) existing entities, not to mention the class of non-existing entities.

This line of argument will surprise anyone with a certain (Berkeleyian) understanding of Husserl's so-called transcendental idealism, which we will need to address briefly. In spite of other claims, Husserl himself is absolutely clear about the experience-independent existence or objectivity (so to speak) of some objects; their status as objects in the existential sense, i.e. as real or ideal entities does not rest on the fact that they are being currently intended or have been intended: they appear as existing independently of us, so the existential notion and the intentional notion of object-hood do not simply collapse into each other. There are for Husserl several classes of objects whose existence is independent from the "actuality of an originarily giving consciousness or respective habituality (possibility of recollection)" (Hua XVII, p. 392). This explicitly holds for ideally existing objects since "their current being-cognized, being-originarily given, being logically determined, being thought of in theoretical contexts is non-essential to them. They are as ideal correlates of the idea of a possible, pure rational epistemic subject in general." (Hua XVII, p. 388)

Speaking in terms of object-theory this implies that object-hood in the intentional sense is not the most fundamental notion in the sense that something can be an object in e.g. the existential sense without being (individually) intended. Indeed, most entities whose existence we are happy to posit will never be intended by a subject (think, again, of individual particles, any amount of natural numbers etc.) Therefore, Husserl is not a Berkeleyian subjectivist or idealist: existence is not produced through the intentional acts of a (divine) subject. We will get back to the issue of Husserl's idealism below.

So far we have covered cases of entities which are objects in all senses (table, Platonic bodies), some things which are objects in all but the existential sense (largest number, ideal table) and some things which are objects in all but the intentional sense (most numbers, most particles), although the latter still need to be intendable or manifestable in some way. The intentional and the existential concepts thus turned out to be not co-extensional. This leaves us with the numerical and the logical notions of object-hood. As we shall see, they are closely related, so for the time being we are going to treat them as one. Are they co-extensional with the formal notion? For is not something necessarily something identical, whether it is intended or exists or not? Where (and maybe even: how?) are we to look for something which is not identical to itself and about which no predications are possible? 
In accordance with phenomenological methodology, we ought to reflect on how identical objects are given. They are constituted in acts of identification. These syntheses of identification, which allow an identical something to appear as such, work on what Husserl calls the "field of passive pre-givenness" (1999, p. 74), which is "not a field of objects in the proper sense. For after all an object is [...] the product of an objectifying, egoic activity/achievement [Leistung]" (Husserl 1999, p. 75). It is within this proto-objective field that we might find something which is not identical.

This field is ordered through associative genesis; its denizens or elements are indeed not identical, they form a manifold of units only in the vaguest sense. Genetically speaking, before identity come heterogeneity and homogeneity; passive syntheses of alignment (Deckung) precede active syntheses of identity. These passive syntheses-or rather their results-however exhibit "affective power" (Husserl 1999, p. 79), forming focal points for attentional modifications and more active syntheses, through which we in turn constitute objects in a stronger sense. The field is that of sensed hyletic data, not identical objects. While matter (=hyle) is necessary for the constitution of objects in the stronger sense (Hua XVII, p. 382), hyle is barely something: "The sensed remains undetermined and inchoate; it is only by apprehending and interpreting it as something that a full-fledged object is constituted." (Zahavi 2017, p. 110) If objects are "(re-)identifiable units of [...] syntheses of identification" (Erhard 2014, p. 513), then the units of of the pre-objective field are not. These units are something, but they are not identical, they are (therefore) not the individual substrates of true predications (we only talk about them in general), they are (passively, yet maybe not individually) intended, they are not real or ideal entities (they are at most "reell", i.e. immanent rather than "real" or "ideal"). This realm of minimal or proto-objects is usually hidden, as it only comes into view within acts of reflecting on the structures and processes of consciousness as opposed to being engaged with the world in the natural attitude.

To recapitulate. To the group from above, which included maximal objects (tables, Platonic bodies), non-existing objects (largest number), non-intended objects (particles), we have now added a second group, which comprises non-identical and therefore non-substrate objects (hyletic data). The (static) problem of extensions now has a negative solution: apart from the numerical and the logical notions, the different concepts of object-hood are not all co-extensional since we have found entities for each concept to which this concept does not apply, but (some of) the others.

\section{Relations}

The passive constitution of the minimal proto-objects and the active constitution of the maximally objective objects lie at the extremes of a genetic spectrum or layering, with the constitution of full-fledged objects requiring an abundance of processes grounding it. While phenomenology locates proto-objects already on the lowest level of the primordial sphere, full-fledged objects (which tick all boxes of our object-concepts) not only require a layer of perception but that of logical acts of predication (which in turn require conceptual abilities, which require the acquisition 
of types etc.), as well as established intersubjectivity, since a crucial moment of the meaning of existence (be it real or ideal) is the availability of the entity in question to a manifold of subjects (cf. Hua IV, p. 389). For something to appear as an existing object, to be constituted as real or ideal, it needs also to be an object in all other senses. The group of non-intended existing entities we have discussed above is an abstraction based on the self-givenness or immediate appearance of particular existing objects. So while there certainly are entities of which we can say that they exist without being intended individually, the existential notion of object-hood is still constitutionally grounded in all other notions; it forms the uppermost layer so to speak. We now turn to the task of exploring this layering, i.e. the connections and relations between the different concepts of object-hood in terms of constitution.

Husserl's terminology tends to fluctuate slightly, but in general he seems to think that the main junction within this layering lies at the point where we start to perform what he calls "logical syntheses", i.e. syntheses of identification. Only "logically formed" objects are "proper objectualities [eigentliche Gegenständlichkeiten]" (Hua XXXIX, p. 69). Logically formed objects are considered to be "primary objectualities" by Husserl as opposed to "secondary objectualities", which are merely "potential unities" and "implicit objectualities" (Hua XXXIX, p. 8), like our proto-objects within the field of passive pre-givenness. Such implicit objects also include the correlates of perception, which he calls "sensual objects" in the Logical Investigations, as well as the topical themes of phenomenological research themselves, namely acts of constitution, structures of consciousness, and the aforementioned minimal (hyletic) proto-objects. The being of these implicit or secondary objects is a necessary implication of any constitution, for "all objects stand-qua constituted-in essential relations to immanent objects", namely those structures and processes enabling the constitution itself. If an object is constituted, many "implicit objectualities are constituted, e.g. the perspectives, or, finally the sensational data/percepts" (Hua XVII, p. 294). The explication of these implicit objects, i.e. the objectification and "logification" of these possible objects is the very task of phenomenology.

Given that Husserl constantly speaks of objects of perception which are explored and explicated pre-predicatively, why exactly is he so hesitant to grant proper objecthood to these intenta of perception? Surely the objects of perception do not lack identity? We rarely see anything non-self-identical after all. However, perception in the narrow sense of a sensual presentation of some content alone is no fully objectivating achievement for Husserl because proper object-consciousness implies a "synthesis of recognition" (Hua XVII, pp. 165, 169; cf. Erhard 2014, p. 522). An object as something identical needs to be presented as an ideal identity-pole, transcending any one experience of it (Hua XVII, p. 174); perception can only ever present similarity, not identity. Once logical acts are in play, we can in some sense perceive identical objects, since our acts of perception become-roughly speaking - conceptually or categorially loaded. One might also speak of objects of perception in the sense that while they might not be constituted in acts of identification, they can still be classified as indentifiable. This would correlate with a weaker notion of object-hood than the mathematical or logical one, which requires identity rather than mere identifiability (Hua XVII, p. 164). Objects of logic have the sense or meaning of enduring validity, they have objective existence in their documented form/in the form of 
documents; they are intersubjectively identifiable: the "objective" of logic is not just fleetingly present in its "thematic field", but "identical in repetition" (Hua XVII, pp. $37,44)$, which does not necessarily hold for objects of perception.

This is not to say that pure perception plays no role in the constitution of objects proper; quite to the contrary, the ideal unity of identity can only show itself if the logical synthesis can operate on the continual synthesis of manifold acts of perceptions (Hua XVI, p. 155). This in turn requires some form of memory or recollective synthesis of the underlying acts of perception. Without recollection, all talk of the same, of any proper object would be "senseless" (Hua XVII, p. 291). The original appearance and endurance of an immanent datum for example do not per se constitute an object in the mathematical sense; recognition (and therefore recollection) is required to establish identity. As such any act of constituting a proper object is historical in that it is grounded in preceding acts of a different type (Hua XVII, p. 257), and it is logical in that the constitution of strict identity requires more than mere perception can deliver. Thus most animals might not be dealing with objects in this sense. Husserl himself asks whether a jellyfish might be the subject of objectconstitutions (Hua XVII, p. 383), but as long as we have not heavily underestimated the logical abilities of jellyfish, the answer seems to be simply: no.

Yet why does Husserl call those acts which constitute identity "logical syntheses"? According to what we have called the "logical" concept of object-hood, an object is the substrate or subject of (possible) (true) predications. And again it seems as if there could be nothing below or beyond this definition, since whatever would fail this definition, it would be true about it that it failed the definition. Whatever is not an object in the logical sense is therefore an object in the logical sense, because it would at least be true of it that it is no object in the logical sense. Thus the idea of something which is not the substrate or subject of (possible) (true) predications appears to be contradictory: obviously there is no identical something of which we might truthfully say that it is not a logical object. But as we have just seen, the appearance of something (as) identical is genetically grounded in pre-objective layers, about which we can talk and which we can identify according to their role in the genesis of proper objects, but whose elements are not themselves strictly identical somethings.

Husserl's point is that being a substrate or subject itself requires certain constitutive acts, namely those of identification; substrates of predication do not occur naturally and completely independent of subjectivity so to speak. The structure of a substrate or logical subject requires "cognitive performances" (Hua XVII, p. 452), especially a "synthesis of recognition" (Hua XVII, p. 165) and further categorial, syntactical formations. The reason being that before we can start predicating, the substrate needs to be stable enough to function as the logical subject of the predication, so to speak. It needs to be presented in such a way as to accept determinations, it has to be picked out: identified-in this, Husserl's transcendental idealism resembles Putnam's internal realism, as Zahavi has pointed out (Zahavi 2017). Once the substrate is determined, we can in full evidence predicate all manner of things of it, for example that it exists independently and has existed independently of our own finite existence etc. 
While the pre-predicative sphere certainly contains certain syntactical formations (Hua XVII, p. 220) and provides perceptual types and the constitution of sundry relations, the "syntactical form" of identity is only given to something undergoing acts of recognition (Hua XVII, p. 115) or outright thematisation. Only once something has become an identical "thema" it is available as "substrate-objectuality" (Hua XVII, p. 120) for acts of predication (judgements) and conceptual explication as opposed to perceptual explication and exploration (Husserl 1999, §24). These logical objects can then in turn become the objects of acts of abstraction, generalisation or formalisation, leading to higher-order "general objects" (Husserl 1999, Section III, titled "The Constitution of the General-Objectualities and the Forms of Judging-In-General") like kinds, species, sets, eidê etc. From these considerations it should be clear that being an object in the logical sense requires having been an object in the intentional sense, specifically an intentum of acts of logical synthesis. Nothing can be a substrate for predication without having being synthesised, i.e. previously intended in logical acts. Logical object-hood genetically presupposes intentional object-hood.

The connection between the logical and the intentional notions of object-hood is still more complicated than that however. For one core link between the various notions is truth. According to Husserl's theory of truth, truth requires the possibility of self-givenness of (a) the state-of-affairs judged to hold and (b) the subject of predication. "To the possibility of a true sentence belongs a priori the possibility of demonstration and this demands originarily giving intuition for the intended state-of-affairs and therefore also for the object-about-which, meaning the one to be determined." (Hua XXXVI, p. 146) To be the subject or substrate of a possible true predication requires that this substrate exhibit the possibility of appearing directly or evidently - "in the flesh", as Husserl is fond of saying-to whomever is performing the predication. Thus the subject of possible true predication is not just the intentum of acts of logical synthesis, but also a possible intentum of acts of intuition, an object of evidence.

The possibility of presence or originary givenness is reserved for proper entities in Husserl's eyes. As noted above, this includes perceivables like my table as well as so-called abstract objects like natural numbers or the Platonic bodies, but excludes impossibilia for example. The largest natural number cannot be originarily given. We can only intend it emptily, through a merely signifying act. Thus-surprisingly - the logical notion of object-hood also seems to imply the existential one.

This relation between logical and existential object-hood implies obvious contradictions. Presumably we can truthfully say of any non-existent topical theme that it does not exist, as long as it is self-identical. But then the non-existent is the subject of a true predication. Yet according to the implication between truth and existence, this implies its existence, contradicting its original determination as non-existent. This issue re-appears with the intentional notion of object-hood too, since the same non-existent topical theme is-qua being thematised-the intentum of an act: I can emptily intend impossibilia. Thus it would at least be true about an intended impossibile that it is an intentum (and impossible of course). But if that were true about it, it would have to exist, due to the strong connection between truth and existence. So again, the relation between truth and existence seems to force us to accept the 
existence of non-existent objects, even if we start from the intentional notion of object-hood which is in and of itself neutral in regard to existence.

One way out of this situation would be to conceptualise the relation between truth, evidence/intuition, and existence/being as pertaining only to states-of-affairs rather than to the substrate of predication or the intentum as well. Hence there could be evident truths about not-self-giveable objects (in any sense), for example that they cannot be intuited. What would be self-given would be the (existing) state-of-affairs, in this case the very fact that an object cannot be intuited (for whatever reason). In this case there could still be something that is a logical as well as an intentional object, but not an object in the existential sense, just like we stated in $\$ 2$ in regard to the largest natural number: it is provably the case that the latter does not exist.

This contradicts some of Husserl's statements regarding the connection between truth and evidence (including the one given above), but as we have seen, these cannot stand. Either we drop the necessary possibility of intuiting the substrate of every true predication, as outlined above, or we drop the claim that some substrates cannot be self-given for non-contingent reasons; after all, the claim that contradictory objects cannot be self-given has been doubted (cf. Priest 1997).

After having disentangled the relation between the logical and the existential notions somewhat, the relation between the intentional and the existential notions remains firmly tangled. For as we have noted above, Husserl is no Berkeleyian idealist. However, while he countenances entities which exist, but are not intended, he also posits the essential necessity for any object to be-in some sense-able to appear or be constituted: "An object is well possible, without me or anyone else actually thinking about it [...] But principally an object is unthinkable which lacks the ideal possibility of experience" (Hua XXXVI, p. 146; cf. Hua XXXV, p. 279). This includes real objects as much as ideal objects: "no object is thinkable as reality without real subjectivity which is able to realise this object in actual cognisance." (Hua XXXV, p. 277) Being an object in the existential sense implies the (possibly counterfactual) possibility of valid cognizance of the object by a subject (Hua XXXVI, p. 132). "A being which could not be intended [...] is meaningless." (Hua XXXIX, p. 726) "Absolute being of a nature, a being which would be substantial in the old sense is unthinkable." (Hua XXXV, p. 279; cf. Hua XXXVI, p. 61) Any object, however formal or emptily it is thought of, is only thinkable as correlate of an intentional constitution inseparable from it (Hua XVII, p. 256).

This infamous notion of constitution has given rise to many misunderstandings, especially if combined with a biased reading of Husserl's self-description as a transcendental idealist. Such misunderstandings-which seem to result mostly from a lack of knowledge of the actual texts-present Husserl as an extreme subjectivist/solipsist on the far side of (bad readings of) Berkeley. Yet because "the constitutive process must be understood as a process that permits that which is constituted to appear, unfold, manifest, and present itself as what it is" (Zahavi 2017, pp. 114-115), constitution is not to be construed as construction or production and not all existence as dependent on current acts of consciousness.

Husserl's transcendental idealism has accordingly no problem admitting the existence of objects independent of any current or actual experience; what matters is manifestability: "Objects have their manifest properties even when not being 
experienced, and can also truthfully possess them before the emergence of conscious creatures and after their eventual extinction. They exist in public space and are intersubjectively accessible and are to that extent given as transcendent; but as essentially manifestable, they do not have a nature that transcends what can be given in experience." (Zahavi 2017, pp. 113-114) In other words, there is no requirement of manifestation, only a requirement of manifestability. For Husserl, nothing ought to be considered an existing object which could never in any circumstance manifest itself for, or appear to, a subject. The somewhat tricky question of how "manifestability" or "intendability" are to be defined and spelled out exactly, is outside the scope of this paper.

The way this appearing or manifesting occurs is irrelevant for the intentional object-hood of whatever appears. Something appearing in perception is as much an intentional object as something which appears in categorial intuition, imagination, or memory. This also covers the everyday usage of "object" as in "object of interest" or "object of study". The very etymology of "object" suggests a correlation of object and subject: something is an object insofar as it is-in some way-towards or for a subject (Figal 2006, p. 126), which in turn is defined as whatever has or confronts objects. "Objects are constituted by subjects; their manifestation is always a manifestation for somebody." (Zahavi 2017, p. 107) But the correlation goes both ways: "One can very well say: no object without subject as well as no subject without object." (Hua XXXV, p. 277) Something is a subject only if it constitutes objects for Husserl. The core of the subject will form the topic of our last section.

To recapitulate: The different notions of object-hood are not only not co-extensional, they form a layer in terms of genetic phenomenology: something (1) nonidentical is given in passive synthesis, a minimal form of intentionality (2); these hyletic data are then synthesised into numerical objects (3), substrates (4), which might then also appear as existing objects (5), given the right acts. After these various acts of constitution have run their course, abstractions, reflections, and reconstructions then lead to our comprehending groups of objects as well as non-intended, non-identical, or non-existing objects.

\section{The Limits of Object-hood}

After having considered the extensions of and relations between the different object-concepts, the question remains whether there is-for Husserl-anything that is not an object at all in any sense, i.e. something outside the "layer of objectualities". Prima facie this seems to require not much thought, since something that is not an object is at least something-and thus still an object in at least the formal sense. And for it to be truly determined as a non-object, it would have to be constituted as such, thus making it an object in the intentional sense as well as the logical one. Apparently there can be nothing in the scope of phenomenology that is not an object, simply because being-in-the-scope-of-phenomenology would make it a formal, an intentional and a logical object (of phenomenological theory). After all even the subject is an object, namely the object of phenomenological inquiry and 
reflection (cf. Hua XXXIV, p. 309, Hua XXXVI, p. 70) or the object of empathy, concern, (self-)understanding etc.

Despite this, Husserl insists that the core of (transcendental) subjectivity is no object. Husserl has many names for what we have called "core". He calls it "urI" or "the absolute flow" (of time-consciousness) or simply "the absolute." In the context of genetic phenomenology, and especially in the discussions of inner timeconsciousness, he names the level on which we encounter this absolute the "archai", the "rhizomata pantôn", the "ur-ground", "ur-sphere" or "ur-level" (HuaMat VIII, p. 4). In an especially poetic turn he even quotes Goethe's Faust II and speaks of the "realm of the mothers" (cf. Arnold 2019). All these phrases however always refer to the unconditioned and unconstituted origin of time and consciousness itself. And this de-objectivation of the absolute is no mere whim. He stresses it in the context of the early Vorlesungen as well as the Bernau Manuscripts and then again in the C-Manuscripts, so we can plausibly claim that the non-objectifiability of the core of subjectivity was a concern of his throughout his writings. The absolute flow is "not an object" (Hua X, p. 112); the I "is not 'being', but the counterpart for all being, not an object, but primal subject [Urstand] for all objectuality. The I should not be named I, and not be named at all, because then it has become objectual. It is the nameless above everything graspable, not standing over all, not hovering, not being, but "functioning"" (Hua XXXIII, p. 277). The term "Urstand" plays on the literal meaning of "Gegenstand", namely "standing-against", which in turn was a translation of the latin "obiectum" as that which was "thrown against" the subject. "Urstand" in this sense is the ultimate subject against which all objects are thrown, against which all Gegenstände stand, so to speak. ("Urstand" is neither a reference to the theological notion of "Urstand" as the state before the fall nor to the linguistically isolated "Urständ", which appears in the phrase "fröhliche Urständ feiern" and means "resurrection". Within philosophy the term was used by the mystic Jakob Böhme and Schelling in ways similar to Husserl's.) Finally, the ur-I of the C-Manuscripts lies below or before all "ontification or objectification" (HuaMat VIII, p. 198).

The question then is whether and how we can consistently and justifiably say anything about the absolute: "But how can that become objectual which is not an object, how can become graspable what is atemporal, supertemporal and can still only be found as temporal in grasping it?" (Hua XXXIII, p. 278) As a non-object, "the living source-point [...] is essentially not directly perceivable." (Hua XXXIII, p. 287) Here Husserl certainly sounds a lot like Schelling, who identifies the absolute with freedom, saying: "There is a contradiction inherent in the idea that freedom ought to be known. It is the absolute subject=Urstand; how could it become an object?" (Schelling, Erlanger Vorlesung, p. 29, quoted from Iber 1994, p. 240)

What exactly is Husserl talking about, in that case? And how can he support his claims according to the principle that all phenomenological assertions should rest on direct intuitions, since intuitions are at least intuitions of something? After all, every act of intuition ontifies, objectifies, temporalises its topical theme (cf. Derrida 2001, p. 205; Sakakibara 2010, pp. 255-256). In fact, any thematisation whatsoever (a) makes its theme into an object according to concepts (1)-(4), since a topic or theme is something identical, intended and predicated about; moreover, thematisation also 
(b) rests on pre-givenness, which at least implies object-hood in the formal sense as the pre-given is something pre-given (1).

The same holds for reflection as a specific kind of thematisation, including phenomenological reflection. Reflecting means "directing-myself toward something which is already there for me, already conscious and simply not thematically experienced, not attended to." (Hua XV, pp. 492-493) "What this ascending reflection finds, is always already there for the I." (Hua XXXIV, p. 209) "A non-reflexive environment is necessary." (Hua XXXIII, p. 282) In this sense, phenomenological inquiry can be described by the Platonic concept of "anamnesis", "recollection" (Arnold 2017, §20), in that it explores what is already there, it explicates what is implicit. But what is implicit is at least something. Phenomenology is thus not creative in the sense that it creates its objects; rather, it intuits-and then describessomething which is already there. Although the sphere of transcendental subjectivity and its eidetic structures does not exist like mundane objects exist, they are not made, but thematised, intuited, described and explicated by phenomenology. In this, phenomenology is supposedly no different from any other thematising activity: "every topic/theme presupposes a pre-thematic, an inauthentically thematic universe" (Hua XXXIV, p. 53; cf. Zahavi 2010, p. 326).

So if Husserl denies object-hood of the absolute tout court, he seems to generate the immediate contradiction of making the absolute into a substrate of predication again in the course of this very denial, as well as excluding it from being any kind of object of phenomenological inquiry.

Note that the problem here is not just the so-called "paradox of subjectivity" in disguise. This paradox revolves around the incompatibility of two descriptions of the subject, namely as subject for the world and object in the world (cf. Carr 1999, p. 135). But in our case the distinction between empirical and transcendental perspectives is not relevant, because Husserl is not simply claiming that transcendental subjectivity is not an empirical object (a really existing object in our sense). That would not be a problem from a transcendental point of view, but a tautology. Husserl's claim appears to be more extreme, as he claims that the absolute is not an object, without further qualifications and in the strongest terms, even negating being in any sense of the absolute. To avoid confusion, we shall call this the "paradox of the absolute".

Husserl's concept of the absolute is a thorny issue, and it might well be the case that Husserl has no consistent theory of it. If we are not willing to accept this rather uncharitable solution to the paradox of the absolute, we have at least two options, for if the claim "the absolute is not an object" generates a contradiction, we can either look at the subject or the predicate to avoid such an outcome. So we can either (a) take his more henological (to borrow a term from the Platonic tradition) descriptions with a pinch of salt and thus weaken the predicate towards something like "the absolute is not an object in every sense" or (b) take his descriptions seriously, but have them be about our limits of thematisation rather than about a paradoxical something which at the same time is said not to be something at all and thus end up with something like "the concept 'object' does not encompass a totality". 
These two options are not mutually exclusive, I think, and are open to additional considerations concerning the living present and the issue of temporalisation/ phenomenalisation.

According to (a) we simply have to be careful not to substantialise the core of subjectivity: the subject is not an existing thing like a table or the number 2 . It is not an object in an overly robust or materialist sense, it is not a thing. On this reading, Husserl warns us against reifying subjectivity. Additionally we are not usually acquainted with the absolute (= ourselves as transcendental subjects) in an objectifying manner, i.e. we are usually not present to ourselves as a topical theme or something we actively constitute in logical acts, but pre-reflexively; so mostly, the absolute would not be an object but in the formal sense.

In phenomenological theorising the absolute would then certainly become an object in all but the existential sense, because even theories about pre-reflexive consciousness have this very pre-reflexive consciousness of ourselves (and everything involved) as topical theme-and a topical theme is an object in the formal, logical, and intentional senses. And since the ego functions as the identical pole for all acts, it must also be-in some sense-identical, even though not in the same sense as all other numerical objects. After all, it precedes and enables all acts of identification. And this very precedence can be reconstructed successfully. It is also the condition for it to be available to phenomenological reflection. The absolute would then be at least an object in the formal sense, available to thematisation and thus further objectification.

This solution would negate Husserl's own insistence on the profound problems generated by reflections on the absolute, but it would give us a consistent theory about the absolute, which we can now objectify to our hearts desire, but should never reify-in our terminology: which we can objectify according to notions (1)-(4) but not (5): transcendental subjectivity is an object qua topic, but neither real like spatio-temporal things nor ideal like mathematical entities. This would also be in tune with Husserl's anti-naturalism, according to which pure subjectivity cannot be consistently described in natural categories. This (deflationary) treatment of the paradox of the absolute then leads back to the more familiar issues surrounding the above-mentioned paradox of subjectivity and the duality of transcendental and empirical subjectivity or rather transcendental and empirical perspectives on subjectivity. This way of dealing with the paradox of the absolute would not solve, but dissolve it: there is no paradox, there are just hyperbolic (but otherwise plausible) warnings against reification.

According to (b) we take Husserl as describing something like the necessary incompleteness of reflection. This interpretation would place Husserl firmly within a deep tradition of metaphysical thought which begins with Plato and leads up to Levinas and Derrida (cf. Arnold 2017, section F; Arnold 2019). On such a reading Husserl ought to be counted among the many thinkers who have discovered an aspect of the complex relation between objectifying reflexivity and postponement or displacement (cf. Schällibaum 2001): "absolute reflexive insight" (Hua III, p. 151) in the sense of bringing everything all at once into view turns out to be impossible because we cannot bring the view itself into view; reflecting on the act and structure of reflecting itself necessarily leads to a shift or withdrawal which precludes the 
completion of the reflection. This shift is part of what Fink called "operative adumbration" (Fink 1957; cf. Zorn 2016, chap. 2.1), i.e. the occlusion of some of the conditions of possibility of philosophical thought for philosophical reflection. Even using a concept like "something" we cannot encompass everything in reflection, but without being able to directly say what is not objectified. The mere "functioning" Husserl speaks of, the "not being," does not indicate properties of something but refers to the fact that objectification can never be completed.

We can however in some sense reconstruct this a-totality or incompleteness of objectifying reflection within reflection itself (as we are doing right now) by reflecting on our experiences and acts which "indicate" or "refer back" (Hua XXXIII, p. 278) to what Husserl calls "the absolute", which we now understand not as a quasiobject but the lack of object-hood. This reflexive reconstruction would necessarily fail to contain the absolute (because there is no object to contain), but it would successfully present the phenomenon of a-totality, incompleteness, absolute withdrawal or "anonymity", as Husserl puts it (cf. Held 1966, pp. 118-122). Terms like "the absolute" would then only refer to a virtual object, a placeholder, a fiction; we would have to read them as metaphors, referring to either a process of withdrawal without object (from a perspective of genetic phenomenology) or the fact that "object" (in any sense) does not encompass everything (from a static perspective). ${ }^{1}$

This insight constitutes the first meta-phenomenological lesson we learn from our considerations of (the limits of) object-hood. The paradox of the absolute is only generated by our attempts to grasp something as not-something or not-something as something; it rests on a (reflexive) misunderstanding. ${ }^{2}$ Similar to the first interpretation, this approach to the paradox of the absolute would not solve but dissolve it: there is no absolute, just the necessary incompleteness of philosophical reflection"withdrawal" as we have called it.

"Alas-withdrawal is not nothing," as Heidegger notes (1976, p. 134), but something we can in fact find in reflection. Withdrawal as we have described it is itself an object according to our notions (1)-(4). Qua philosophical topic it is something (1) intended (2), even something identical (3), repeatedly (and accurately) described in various phenomenological ventures by different authors (4). ${ }^{3}$ This objectification is no accident. For while the concept "object" does not encompass everything, wherever we direct our inquiring gaze, we necessarily objectify and thus deal with objects. Not everything is an object, but anything we thematise is. Husserl himself

\footnotetext{
${ }^{1}$ Herein I see a congruence with Markus Gabriel's ontology, according to which objects exists by appearing in a field of sense, which implies that "it is impossible that everything is determinately an object or a fact at any given time" (Gabriel 2015, p. 253). Employing a term by DeLanda, Gabriel calls any ontology (or metaphysics) "flat" in which there are just co-existing objects. His own new realism is therefore non-flat. My rereading of Husserl's theory of the absolute leads to a non-flat phenomenology in parallel to Gabriel's non-flat ontology; indeed what Husserl calls "the absolute" is simply the name for the fact that phenomenology is not flat in this sense.

2 A thorough discussion of the structural features of such problems can be found in Zorn (2016, esp. pp. 283-296).

${ }^{3}$ One might for example add Derrida's differance to the terms we have used to denote what we have called "withdrawal". The transcendence of the other in Levinas also seems to present an example of the limits of object-hood.
} 
tentatively asks whether his "reflexive inquiry" (Rückfrage) does not necessarily lead to an "apperceptive unity" (HuaMat VIII, p. 118), i.e. a constituted, identical object, which implies that the very effort of reflecting on the absolute, conceptualised as something which is at the same time supposed to be no object, precludes its success.

This results in the second meta-phenomenological lesson we can learn from reflecting on the limits of object-hood: we cannot escape objectification once engaged in a thematising activity like phenomenological reflection. As it turns out, this holds even for the examination of the very limit of object-hood itself, the socalled absolute.

Acknowledgements Open Access funding provided by Projekt DEAL.

Funding Funding was provided by DAAD (Grant no. 91671488).

\section{Compliance with Ethical Standards}

Conflict of interest The corresponding author states that there is no conflict of interest.

Open Access This article is licensed under a Creative Commons Attribution 4.0 International License, which permits use, sharing, adaptation, distribution and reproduction in any medium or format, as long as you give appropriate credit to the original author(s) and the source, provide a link to the Creative Commons licence, and indicate if changes were made. The images or other third party material in this article are included in the article's Creative Commons licence, unless indicated otherwise in a credit line to the material. If material is not included in the article's Creative Commons licence and your intended use is not permitted by statutory regulation or exceeds the permitted use, you will need to obtain permission directly from the copyright holder. To view a copy of this licence, visit http://creativecommons.org/licen ses/by/4.0/.

\section{References}

Arnold, Th. (2017). Phänomenologie als Platonismus. Berlin/Boston.

Arnold, Th. (2019). In the 'realm of the mothers'. On the absolute in Husserl's phenomenology. In:

Rohstock, M., Plevrakis, E. (Eds.), Grundlegung des Absoluten? Paradigmen aus der Geschichte der Metaphysik (pp. 279-304). Heidelberg.

Carr, D. (1999). The paradox of subjectivity. Oxford/New York.

Derrida, J. (2001). Writing and difference. London.

Erhard, Ch. (2014). Denken über Nichts. Intentionalität und Nicht-Existenz bei Husserl. Berlin/Boston. Figal, G. (2006). Gegenständlichkeit. Das Hermeneutische und die Philosophie. Tübingen.

Fink, E. (1957). Operative Begriffe in Husserls Phänomenologie. Zeitschrift für philosophische Forschung 11(3): 321-337.

Frege, G. (2008). Funktion, Begriff, Bedeutung. Göttingen.

Gabriel, M. (2015). Fields of sense. An new realist ontology. Edinburgh.

Gödel, K. (1995). The modern development of the foundations of mathematics in the light of philosophy (1961). In: Feferman, S., et al. (Eds.). Kurt Gödel collected works III: Unpublished essays and lectures. New York.

Heidegger, M. (1976). Was heißt Denken. In: Wegmarken. Frankfurt.

Held, K. (1966). Lebendige Gegenwart. Den Haag.

Husserl, E. Husserliana. Den Haag/Dordrecht/Heidelberg/London/New York/Boston/Lancaster.

Hua III. Ideen zu einer reinen Phänomenologie und phänomenologischen Philosophie. Volume I. K. Schuhmann (Ed.). 1976. 
Hua IV. Ideen zu einer reinen Phänomenologie und phänomenologischen Philosophie. Volume II. M. Biemel (Ed.). 1991.

Hua XV. Zur Phänomenologie der Intersubjektivität. Texte aus dem Nachlass. Dritter Teil: 1929-1935. I. Kern (Ed.). 1973.

Hua XVI. Ding und Raum. K.-H. Hahnengress and S. Rapic (Eds.). 1973.

Hua XVII. Formale und transzendentale Logik. P. Janssen (Ed.). 1974.

Hua XXXIII. Die Bernauer Manuskripte über das Zeitbewusstsein. R. Bernet and D. Lohmar (Eds.). 2001.

Hua XXXV. Einleitung in die Philosophie (1922/23). B. Goossens (Ed.). 2002.

Hua XXXVI. Transzendentaler Idealismus. Texte aus dem Nachlass (1908-1921). R. D. Rollinger and R. Sowa (Eds.). 2003.

Hua XXXIX. Die Lebenswelt. R. Sowa (Ed.). 2008.

HuaMat VIII. Späte Texte über Zeitkonstitution (1929-1934). Die C-Manuskripte. D. Lohmar (Ed.). 2006.

Husserl, E. (1999). Erfahrung und Urteil. Hamburg.

Iber, Ch. (1994). Das Andere der Vernunft. Berlin.

Keiling, T. (2010). Gegenstand. In: H.-H. Gander (Ed.), Husserl-Lexikon. Darmstadt.

Kobusch, Th. (1984). Gegenstand. In: J. Ritter (Ed.), Historisches Wörterbuch der Philosophie. Basel.

Laycock, H. (2010). Object. In: E. N. Zalta (Ed.). The Stanford encyclopedia of philosophy (Winter 2014 Edition). URL $=<$ https://plato.stanford.edu/archives/win2014/entries/object/ $>$.

McGinn, C. (2000). Logical properties. Oxford.

Priest, G. (1997). Sylvan's box. Notre Dame Journal of Formal Logic, 38(4), 573-582

Putnam, H. (1987). The many faces of realism. Open Court.

Sakakibara, T. (2010). Reflection upon the living present and the primal consciousness in Husserl's phenomenology. In: Lohmar and Yamaguchi (Eds.), On time (pp. 251-272). Dordrecht/Heidelberg/London/New York.

Schällibaum, U. (2001). Reflexivität und Verschiebung. Wien.

Tugendhat, E. (1976). Vorlesungen zur Einführung in die sprach-analytische Philosophie. Frankfurt am Main (Tugendhat, E. Traditional and analytical philosophy. Lectures on the philosophy of language. Transl. by P.A. Gorner Cambridge: Cambridge University Press, 1982).

Williamson, T. (2000). Knowledge and its limits. Oxford.

Zahavi, D. (2010). Inner (time-)consciousness. In: Lohmar and Yamaguchi (Eds.), On time (pp. 319339). Dordrecht/Heidelberg/London/New York.

Zahavi, D. (2017). Husserl's legacy. Oxford.

Zorn, D.-P. (2016). Vom Gebäude zum Gerüst. Entwurf einer Komparatistik reflexiver Figurationen in der Philosophie. Vol. I, Berlin.

Publisher's Note Springer Nature remains neutral with regard to jurisdictional claims in published maps and institutional affiliations. 